\title{
Carnot Engine: A New Look with Different Real Gas Equations
}

\author{
Debojit Sen ${ }^{1,2}$ and A. Ghorai ${ }^{2}$ \\ ${ }^{1}$ Department of Physics, Maulana Azad College, Rafi Ahmed Kidwai Road \\ Kolkata, India \\ Email: sendebojit965 [AT] gmail.com \\ ${ }^{2}$ School of Science, Jangalpur Road \\ Kolkata, India \\ Email: amitavaghorai61 [AT] gmail.com
}

\begin{abstract}
The efficiency of Carnot engine, an important machine in classical thermodynamics, depends only on the temperatures of source and sink reservoirs and is independent of the nature of the working substance. There are several real gas equations which may be used to verify this statement. Here we choose three real gas equations viz. Van der Waal's, Berthelot's and Clausius's real gas equation of state for simplicity for this verification.
\end{abstract}

Keywords - Carnot engine, efficiency, equation of state, entropy, specific heat, Maxwell's TdS relation, Van der Waal's equation, Berthelot's equation, Clausius's equation.

\section{INTRODUCTION}

It is well known that heat of itself will not pass from a lower to a higher temperature and the machine we need is a heat engine consisting of three essential parts, viz. a source, a sink and a working substance. The efficiency of a heat engine $\eta$ is defined as the ratio of output work $\mathrm{W}$ and input heat energy $\mathrm{Q}$ as

$$
\eta=\frac{\text { Output work }}{\text { Input heat }}=\frac{\mathrm{W}}{\mathrm{Q}}=1-\frac{\mathrm{Q}_{2}}{\mathrm{Q}_{1}}
$$

Here the system absorbs heat $\mathrm{Q}_{1}$ from the source; a part of it is converted into work $\mathrm{W}$ and rest of it is rejected to the sink $\mathrm{Q}_{2}$. Efficiency $\eta$ depends on the nature of the working substance, the source at higher temperature, the sink at lower temperature and a working cycle.

Due to inadequacy of ideal gas equation to real gaseous systems literature survey [1-4] gives different empirical real gas equations, viz. Van der Waal's equation, Berthelot's equation, Clausius's equation, Dieterici's equation, Redlich and Kwong's equation, Saha and Bose's equation and Beattie and Bridgeman's equation. Van der Waal's, Berthelot and Dieterici's equations are of limited accuracy. Redlich and Kwong's equation gives good results at high pressure and is fairly accurate for temperatures above the critical value. Saha and Bose's equation of state is quite accurate for densities less than about 0.8 times the critical density.

All the standard text books use ideal gas equation of state for verification. But nowhere details of thermodynamic laws were used. We here made an extensive use of mathematical and thermodynamical skill to verify the independence of real gas equations as the nature of working substance. For simplicity out of all we took one mol of only three different real gas equations as working substance, viz. (i) Van der Waal's real gas equation, (ii) Berthelot's real gas equation and (iii) Clausius's real gas equation of state and extensively used Maxwell's first TdS relation for this verification in the following sections.

In this novel pedagogic work we shall first discuss in short the essence of Carnot engine; next the importance of specific heat at constant volume $\mathrm{C}_{\mathrm{V}}$; the necessity of Maxwell's TdS relation and finally we shall calculate the efficiency of Carnot engine in three different real gas systems.

\section{CARNOT ENGINE}

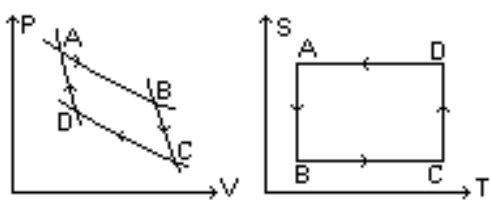

Figure 1 
Carnot engine is an ideal engine consisting of following parts. (i) Heat source at higher temperature $\mathrm{T}_{1}$. (ii) Heat sink at lower temperature $\mathrm{T}_{2}$. (iii) A working substance may be any type of fluid, real or ideal. (iv) A suitable machine known as Carnot machine [1-2] which is a cylinder with perfectly non-conducting walls and perfectly conducting bottom so that heat exchange can take place through bottom only. The cylinder is fitted with a non-conducting piston which is weightless and its motion within the cylinder is frictionless. (v) A working cycle known as Carnot cycle. It is a reversible cyclic process consisting of four successive changes, viz. (a) isothermal expansion, (b) adiabatic expansion, (c) isothermal compression and (d) adiabatic compression. After these four changes the system comes back to the original state.

Generally in ideal Carnot engine we take one mole of monatomic ideal or perfect gas. Let us take one mole of monatomic ideal gas within the cylinder of Carnot engine, a source at temperature $T_{1}$ and a sink at temperature $T_{2}$ with $\mathrm{T}_{1}>\mathrm{T}_{2}$. The initial configuration of the gas is shown in PV and TS indicator diagram of figure 1 at point A with coordinate $\left(\mathrm{P}_{1}, \mathrm{~V}_{1}, \mathrm{~T}_{1}\right)$.
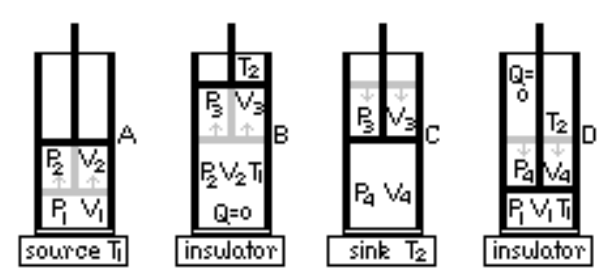

Figure 2

Let the cylinder be placed over the source at temperature $\mathrm{T}_{1}$ (figure $2 \mathrm{~A}$ ). Now to make a quasi-static isothermal expansion the piston is slowly moved in the outward direction. As the piston moves outward, temperature tends to fall and some heat will pass from the source to the cylinder. So the temperature of the cylinder always remains same as $\mathrm{T}_{1}$ and the representative point on the indicator diagram (figure 1) moves from $\mathrm{A}$ with coordinate $\left(\mathrm{P}_{1}, \mathrm{~V}_{1}, \mathrm{~T}_{1}\right)$ to $\mathrm{B}$ with coordinate $\left(\mathrm{P}_{2}, \mathrm{~V}_{2}, \mathrm{~T}_{1}\right)$ along the isothermal curved path. The heat extracted in this isothermal process of expansion is equal to work done by the gas $\mathrm{W}_{1}$ and it is

$$
\mathrm{Q}_{1}=\mathrm{W}_{1}=\int_{\mathrm{A}}^{\mathrm{B}} \mathrm{PdV}=\mathrm{RT}_{1} \ln \frac{\mathrm{V}_{2}}{\mathrm{~V}_{1}}
$$

The source is now removed from the bottom and the cylinder is placed over a non-conducting material cap (figure 2B). Now the piston is allowed to move slowly and outwardly by inertia of motion. So no heat exchange will take place in this quasi-static adiabatic process and the temperature falls to $\mathrm{T}_{2}$. The representative point on the indicator diagram (figure 1) moves from $\mathrm{B}$ with coordinate $\left(\mathrm{P}_{2}, \mathrm{~V}_{2}, \mathrm{~T}_{1}\right)$ to $\mathrm{C}$ with coordinate $\left(\mathrm{P}_{3}, \mathrm{~V}_{3}, \mathrm{~T}_{2}\right)$ along the adiabatic path. The net work done $\mathrm{W}_{2}$ in this adiabatic process of expansion will be

$$
\mathrm{W}_{2}=\int_{\mathrm{B}}^{\mathrm{C}} \mathrm{PdV}=\frac{\mathrm{R}\left(\mathrm{T}_{2}-\mathrm{T}_{1}\right)}{\gamma-1}
$$

This is because $P V^{\gamma}=$ constant and PV $=$ RT for one mole of monatomic ideal gas.

Since pressure is now very much diminished the gas has lost its expansive power (figure $2 \mathrm{C}$ ). So we now replace the non-conducting cap from the bottom of the cylinder by the sink at temperature $\mathrm{T}_{2}$ and compress the gas isothermally along the curved path $C D$ with coordinate of $\mathrm{D}$ is $\left(\mathrm{P}_{4}, \mathrm{~V}_{4}, \mathrm{~T}_{2}\right)$. In this isothermal compression heat developed $\mathrm{Q}_{2}$ will now pass to the sink and it is equal to the work done $\mathrm{W}_{3}$. Thus $\quad \mathrm{Q}_{2}=\mathrm{W}_{3}=\int_{\mathrm{C}}^{\mathrm{D}} \mathrm{PdV}=-\mathrm{RT}_{2} \ln \frac{\mathrm{V}_{3}}{\mathrm{~V}_{4}}$

The negative sign indicates that heat has been rejected by the gas to the sink.

The cylinder is now again placed over the non-conducting cap and a slow adiabatic compression is done on it due to inertia so that the gas returns to the original state at $\mathrm{A}$ through the adiabatic path DA (figure $2 \mathrm{D}$ ). The work done $\mathrm{W}_{4}$ in this case is

$$
\mathrm{W}_{4}=\int_{\mathrm{D}}^{\mathrm{A}} \mathrm{PdV}=\frac{\mathrm{R}\left(\mathrm{T}_{1}-\mathrm{T}_{2}\right)}{1-\gamma}
$$

Now since B and C are on the same adiabatic path so $\frac{\mathrm{T}_{1}}{\mathrm{~T}_{2}}=\left(\frac{\mathrm{V}_{3}}{\mathrm{~V}_{4}}\right)^{\gamma-1}$. Similarly A and D are on another adiabatic path and $\frac{T_{1}}{T_{2}}=\left(\frac{V_{4}}{V_{1}}\right)^{\gamma-1}$. So the total work done by the engine in this cycle is

$$
W=\mathrm{W}_{1}+\mathrm{W}_{2}+\mathrm{W}_{3}+\mathrm{W}_{4}=\mathrm{R}\left(\mathrm{T}_{1}-\mathrm{T}_{2}\right) \ln \frac{\mathrm{v}_{2}}{\mathrm{v}_{1}}
$$

The total heat absorbed by the system is $Q_{1}-Q_{2}=W$. So Carnot engine satisfies first law of thermodynamics because in a cyclic process $\oint \mathrm{dU}=0$. The calculated efficiency of Carnot engine is

$$
\eta=1-\frac{\mathrm{Q}_{2}}{\mathrm{Q}_{1}}=1-\frac{\mathrm{RT}_{2} \ln \frac{\mathrm{V}_{3}}{\mathrm{~V}_{4}}}{\mathrm{RT}_{1} \ln \frac{\mathrm{V}_{2}}{\mathrm{~V}_{1}}}=1-\frac{\mathrm{T}_{2}}{\mathrm{~T}_{1}}
$$




\section{WHY C $C_{V}$ VARIATION IS IMPORTANT}

The above standard procedure can be set aside keeping in view that the laws of thermodynamics and Maxwell's relations are integral part of classical thermodynamics. To illustrate we note that $C_{V}$ the specific heat of real gas at constant volume is not a constant as is so in case of ideal gas and also in case of Van der Waal's real gas. This is due to the fact that

$$
\left(\frac{\partial \mathrm{C}_{\mathrm{V}}}{\partial \mathrm{V}}\right)_{T}=\mathrm{T}\left(\frac{\partial^{2} \mathrm{P}}{\partial \mathrm{T}^{2}}\right)_{V}
$$

So it is now essential to use Maxwell's first TdS relation to account for this variation and so we write

$$
\mathrm{dQ}=\mathrm{TdS}=\mathrm{C}_{\mathrm{V}} \mathrm{dT}+\mathrm{T}\left(\frac{\partial \mathrm{P}}{\partial \mathrm{T}}\right)_{\mathrm{V}} \mathrm{dV}
$$

Here we apply Carnot cycle in TS diagram of figure 1 from point A with coordinate $\left(\mathrm{S}_{1}, \mathrm{~T}_{1}\right)$, to $\mathrm{B}$ with coordinate $\left(S_{2}, T_{1}\right)$, to $C$ with coordinate $\left(S_{2}, T_{2}\right)$, to finally D with coordinate $\left(S_{1}, T_{1}\right)$ to Van der Waal's, Berthelot's and Clausius's real gas equation of state for simplicity for this verification [5-7].

\section{VAN DER WAAL'S REAL GAS}

Although up to 1850 , most scientists believed strictly the simple equation of state PV $=$ RT, but Regnault argued differently. Van der Waal's (1873) approximate real gas equation of state $[6,8]$ for one mole, written as $\left(P+\frac{a}{V^{2}}\right)(V-b)=$ RT, had shown that the cubic equation of state accounted for the essential properties of fluids, and in particular, it predicted the existence of a critical point. Although his equation represented the phenomena in its broad aspect, it left much to be desired from a quantitative point of view. For adiabatic expansion and contraction of real gas $\mathrm{C}_{\mathrm{V}}$ varies with volume $\mathrm{V}$ as $\left(\frac{\partial \mathrm{C}_{\mathrm{V}}}{\partial \mathrm{V}}\right)_{T}=\mathrm{T}\left(\frac{\partial^{2} \mathrm{P}}{\partial \mathrm{T}^{2}}\right)_{V}$ and for Van der Waal's gas $\left(\frac{\partial \mathrm{C}_{\mathrm{V}}}{\partial \mathrm{V}}\right)_{T}=\mathrm{T}\left[\frac{\partial^{2}}{\partial \mathrm{T}^{2}}\left(\frac{\mathrm{RT}}{\mathrm{V}-\mathrm{b}}-\frac{\mathrm{a}}{\mathrm{V}^{2}}\right)\right]_{V}=0$ gives $\mathrm{C}_{\mathrm{V}}=\mathrm{f}(\mathrm{T})$. Now the first TdS relation for reversible isothermal expansion for Van der Waal's gas can be written as

$$
\mathrm{TdS}=\mathrm{dQ}=\mathrm{T}\left(\frac{\partial \mathrm{P}}{\partial \mathrm{T}}\right)_{\mathrm{V}} \mathrm{dV}=\mathrm{T}\left[\frac{\partial}{\partial \mathrm{T}}\left(\frac{\mathrm{RT}}{\mathrm{V}-\mathrm{b}}-\frac{\mathrm{a}}{\mathrm{V}^{2}}\right)\right]_{\mathrm{V}} \mathrm{dV}=\frac{\mathrm{RTdV}}{\mathrm{V}-\mathrm{b}}
$$

We apply this to Carnot cycle in TS diagram of figure 1 from point A with coordinate $\left(\mathrm{P}_{1}, \mathrm{~V}_{1}, \mathrm{~T}_{1}\right)$ or $\left(\mathrm{S}_{1}, \mathrm{~T}_{1}\right)$ to $\mathrm{B}$ with coordinate $\left(\mathrm{P}_{2}, \mathrm{~V}_{2}, \mathrm{~T}_{1}\right)$ or $\left(\mathrm{S}_{2}, \mathrm{~T}_{1}\right)$ to calculate the heat extracted will be

$$
\mathrm{Q}_{1}=\int_{\mathrm{A}}^{\mathrm{B}} \mathrm{TdS}=\int_{\mathrm{V}_{1}}^{\mathrm{V}_{2}} \frac{\mathrm{RT}_{1} \mathrm{dV}}{\mathrm{V}-\mathrm{b}}=\mathrm{RT}_{1} \ln \frac{\mathrm{V}_{2}-\mathrm{b}}{\mathrm{V}_{1}-\mathrm{b}}
$$

For the second isotherm in TS diagram of figure 1 from point $C$ with coordinate $\left(\mathrm{P}_{3}, \mathrm{~V}_{3}, \mathrm{~T}_{2}\right)$ or $\left(\mathrm{S}_{2}, \mathrm{~T}_{2}\right)$ to $\mathrm{D}$ with coordinate $\left(\mathrm{P}_{4}, \mathrm{~V}_{4}, \mathrm{~T}_{2}\right)$ or $\left(\mathrm{S}_{1}, \mathrm{~T}_{1}\right)$ to calculate the heat released will be

$$
\mathrm{Q}_{2}=\int_{\mathrm{C}}^{\mathrm{D}} \mathrm{TdS}=\int_{\mathrm{V}_{3}}^{\mathrm{V}_{4}} \frac{\mathrm{RT}_{2} \mathrm{dV}}{\mathrm{V}-\mathrm{b}}=\mathrm{RT}_{2} \ln \frac{\mathrm{V}_{4}-\mathrm{b}}{\mathrm{V}_{3}-\mathrm{b}}
$$

For the other two isentropic or adiabatic from $\mathrm{B}$ to $\mathrm{C}$ and $\mathrm{D}$ to $\mathrm{A}$ we get from first law of thermodynamics and equation (10)

$$
\mathrm{dQ}=0 \Rightarrow \mathrm{C}_{\mathrm{V}} \mathrm{dT}=-\mathrm{T}\left(\frac{\partial \mathrm{P}}{\partial \mathrm{T}}\right)_{\mathrm{V}} \mathrm{dV} \Rightarrow-\mathrm{f}(\mathrm{T}) \mathrm{dT}=\frac{\mathrm{RTdV}}{\mathrm{V}-\mathrm{b}}
$$

Integrating factor of this equation with $m=\mathrm{f}(\mathrm{T})$ and $n=\frac{\mathrm{RT}}{\mathrm{V}-\mathrm{b}}$ is $n^{-1}\left[\frac{\partial \mathrm{m}}{\partial \mathrm{V}}-\frac{\partial \mathrm{n}}{\partial \mathrm{T}}\right]=-\mathrm{T}^{-1}$. We make the above equation total differential as

$$
\frac{\mathrm{f}(\mathrm{T}) \mathrm{dT}}{\mathrm{T}}=-\frac{\mathrm{RdV}}{\mathrm{V}-\mathrm{b}}
$$

Or,

$$
\begin{aligned}
& \mathrm{d}[\mathrm{g}(\ln \mathrm{T})+\mathrm{R} \ln (\mathrm{V}-\mathrm{b})=0 \\
& \mathrm{g}(\ln \mathrm{T})+\mathrm{R} \ln (\mathrm{V}-\mathrm{b})=\mathrm{constan} \mathrm{t}=\mathrm{c} \\
& \mathrm{m}=\mathrm{f}(\mathrm{T})=\mathrm{c}-\mathrm{g}(\ln \mathrm{T})=\mathrm{R} \ln (\mathrm{V}-\mathrm{b})
\end{aligned}
$$

Or,

Or,

Hence at $B$ and $C f\left(T_{1}\right)-f\left(T_{2}\right)=R \ln \frac{V_{2}-b}{V_{3}-b}$. Similarly for $D$ and $A f\left(T_{2}\right)-f\left(T_{1}\right)=R \ln \frac{V_{4}-b}{V_{1}-b}$. Thus combining these two we get

$$
\ln \frac{\mathrm{V}_{2}-\mathrm{b}}{\mathrm{V}_{3}-\mathrm{b}}=-\ln \frac{\mathrm{V}_{4}-\mathrm{b}}{\mathrm{V}_{1}-\mathrm{b}} \Rightarrow \frac{\mathrm{V}_{1}-\mathrm{b}}{\mathrm{V}_{2}-\mathrm{b}}=\frac{\mathrm{V}_{4}-\mathrm{b}}{\mathrm{V}_{3}-\mathrm{b}}
$$

So for Van der Waal's gas

$$
\eta_{\mathrm{Vdw}}=1-\frac{\mathrm{Q}_{2}}{\mathrm{Q}_{1}}=1-\frac{\mathrm{RT}_{2} \ln \frac{\mathrm{V}_{4}-\mathrm{b}}{\mathrm{V}_{3}-\mathrm{b}}}{\mathrm{RT}_{1} \ln \frac{\mathrm{V}_{2}-\mathrm{b}}{\mathrm{V}_{1}-\mathrm{b}}}=1-\frac{\mathrm{T}_{2}}{\mathrm{~T}_{1}}
$$




\section{BERTHELOT'S REAL GAS}

Berthelot asked if in order to explain the deviations between the equation and the experimental results, it was necessary to modify the evaluation of the internal pressure or that of the co-volume and to eliminate many of the limitations of the Van der Waal's equation Berthelot studied of the properties of gases and fluids and developed a real gas equation [9] for one mole $\left(\mathrm{P}+\frac{\mathrm{a}}{\mathrm{TV}^{2}}\right)(\mathrm{V}-\mathrm{b})=\mathrm{RT}$. This probably was the basis for the development of the Redlich-Kwong equation of state (Redlich and Kwong, 1949). The first TdS relation for reversible isothermal expansion for Berthelot's gas can be written as $\quad \mathrm{TdS}=\mathrm{dQ}=\mathrm{T}\left(\frac{\partial \mathrm{P}}{\partial \mathrm{T}}\right)_{\mathrm{V}} \mathrm{dV}=\mathrm{T}\left[\frac{\mathrm{R}}{\mathrm{V}-\mathrm{b}}+\frac{\mathrm{a}}{\mathrm{T}^{2} \mathrm{~V}^{2}}\right] \mathrm{dV}$

Now for adiabatic expansion and contraction of real gas $C_{V}$ varies with volume $V$ as $\left(\frac{\partial C_{V}}{\partial V}\right)_{T}=T\left(\frac{\partial^{2} \mathrm{P}}{\partial T^{2}}\right)_{V}$ and for Berthelot's gas $\left(\frac{\partial C_{V}}{\partial V}\right)_{T}=T\left[\frac{\partial^{2}}{\partial T^{2}}\left(\frac{R T}{V-b}-\frac{a}{T^{2}}\right)\right]_{V}=-\frac{2 a}{T^{2} V^{2}}$ gives $C_{V}=f(T)+\frac{2 a}{T^{2} \mathrm{~V}}$. We apply this to Carnot cycle in TS diagram of figure 1 from point $A$ with coordinate $\left(\mathrm{S}_{1}, \mathrm{~T}_{1}\right)$ to $\mathrm{B}$ with coordinate $\left(\mathrm{S}_{2}, \mathrm{~T}_{1}\right)$ to calculate the heat extracted will be

$$
\mathrm{Q}_{1}=\int_{\mathrm{A}}^{\mathrm{B}} \mathrm{TdS}=\int_{\mathrm{V}_{1}}^{\mathrm{V}_{2}}\left[\frac{\mathrm{RT}_{1}}{\mathrm{~V}-\mathrm{b}}+\frac{\mathrm{a}}{\mathrm{T}_{1} \mathrm{~V}^{2}}\right] \mathrm{dV}=\mathrm{RT}_{1} \ln \frac{\mathrm{V}_{2}-\mathrm{b}}{\mathrm{V}_{1}-\mathrm{b}}
$$

For the second isotherm in TS diagram of figure 1 from point $C$ with coordinate $\left(S_{2}, T_{2}\right)$ to $D$ with coordinate $\left(S_{1}, T_{1}\right)$ to calculate the heat released will be

$$
\mathrm{Q}_{2}=\int_{\mathrm{C}}^{\mathrm{D}} \mathrm{Td} S=\int_{\mathrm{V}_{3}}^{\mathrm{V}_{4}}\left[\frac{\mathrm{RT}_{2}}{\mathrm{~V}-\mathrm{b}}+\frac{\mathrm{a}}{\mathrm{T}_{2} \mathrm{~V}^{2}}\right] \mathrm{dV}=\mathrm{RT}_{2} \ln \frac{\mathrm{V}_{4}-\mathrm{b}}{\mathrm{V}_{3}-\mathrm{b}}
$$

For the other two isentropic from $\mathrm{B}$ to $\mathrm{C}$ and $\mathrm{D}$ to $\mathrm{A}$ we get from first law of thermodynamics

Or,

$$
\begin{aligned}
& d Q=0 \Rightarrow C_{V} d T+T\left(\frac{\partial P}{\partial T}\right)_{V} d V=0 \\
& {\left[f(T)+\frac{2 a}{T^{2} V}\right] d T+T\left[\frac{R}{V-b}+\frac{a}{T^{2} V^{2}}\right] d V=0}
\end{aligned}
$$

Integrating factor of this equation with $m=\mathrm{f}(\mathrm{T})+\frac{2 \mathrm{a}}{\mathrm{T}^{2} \mathrm{~V}}$ and $\mathrm{n}=\frac{\mathrm{RT}}{\mathrm{V}-\mathrm{b}}+\frac{\mathrm{a}}{\mathrm{TV}^{2}}$ is $\mathrm{n}^{-1}\left[\frac{\partial \mathrm{m}}{\partial \mathrm{V}}-\frac{\partial \mathrm{n}}{\partial \mathrm{T}}\right]=-\mathrm{T}^{-1}$. We make the above equation total differential as

$$
\left[\mathrm{f}(\mathrm{T})+\frac{2 \mathrm{a}}{\mathrm{T}^{3} \mathrm{~V}}\right] \mathrm{dT}+\mathrm{T}\left[\frac{\mathrm{R}}{\mathrm{V}-\mathrm{b}}+\frac{\mathrm{a}}{\mathrm{T}^{2} \mathrm{~V}^{2}}\right] \mathrm{dV}=0
$$

Or,

$$
\mathrm{d}\left[\frac{\mathrm{a}}{\mathrm{T}^{2} \mathrm{~V}}-\mathrm{R} \ln (\mathrm{V}-\mathrm{b})-\mathrm{g}(\ln \mathrm{T})\right]=0
$$

Or,

$$
\frac{\mathrm{a}}{\mathrm{T}^{2} \mathrm{~V}}-\mathrm{R} \ln (\mathrm{V}-\mathrm{b})-\mathrm{g}(\ln \mathrm{T})=\text { constant }=\mathrm{c}
$$

Or,

$$
f(T)=g(\ln T)-c=\frac{a}{T^{2} V}-R \ln (V-b)
$$

Hence at $B \quad f\left(T_{1}\right)=\frac{a}{T_{1}^{2} V_{2}}-R \ln \left(V_{2}-b\right)$ and at $C \quad f\left(T_{2}\right)=\frac{a}{T_{2}^{2} V_{3}}-R \ln \left(V_{3}-b\right)$. Thus $f\left(T_{1}\right)-f\left(T_{2}\right)=\frac{a}{T_{1}^{2} V_{2}}-\frac{a}{T_{2}^{2} V_{3}}-$ $R \ln \frac{V_{2}-b}{V_{3}-b}$. Similarly for D and A $\left(T_{1}\right)-f\left(T_{2}\right)=\frac{a}{T_{1}^{2} V_{1}}-\frac{a}{T_{2}^{2} V_{4}}-R \ln \frac{V_{1}-b}{V_{4}-b}$. Equating we get

Or,

$$
\mathrm{R} \ln \frac{\mathrm{V}_{2}-\mathrm{b}}{\mathrm{V}_{3}-\mathrm{b}}-\frac{\mathrm{a}}{\mathrm{T}_{1}^{2} \mathrm{~V}_{2}}+\frac{\mathrm{a}}{\mathrm{T}_{2}^{2} \mathrm{~V}_{3}}=R \ln \frac{\mathrm{V}_{1}-\mathrm{b}}{\mathrm{V}_{4}-\mathrm{b}}-\frac{\mathrm{a}}{\mathrm{T}_{1}^{2} \mathrm{~V}_{1}}+\frac{\mathrm{a}}{\mathrm{T}_{2}^{2} \mathrm{~V}_{3}}
$$

Or,

$$
\mathrm{R} \ln \frac{\mathrm{V}_{4}-\mathrm{b}}{\mathrm{V}_{3}-\mathrm{b}}-\frac{\mathrm{a}}{\mathrm{T}_{2}^{2}}\left[\frac{1}{\mathrm{~V}_{4}}-\frac{1}{\mathrm{~V}_{3}}\right]=\operatorname{Rln} \frac{\mathrm{V}_{1}-\mathrm{b}}{\mathrm{V}_{2}-\mathrm{b}}-\frac{\mathrm{a}}{\mathrm{T}_{1}^{2}}\left[\frac{1}{\mathrm{~V}_{1}}-\frac{1}{\mathrm{~V}_{2}}\right]
$$

Or,

$$
\frac{\operatorname{Rln} \frac{\mathrm{V}_{4}-\mathrm{b}}{\mathrm{V}_{3}-\mathrm{b}}-\frac{\mathrm{a}}{\mathrm{T}_{2}^{2}}\left[\frac{1}{\mathrm{~V}_{4}}-\frac{1}{\mathrm{~V}_{3}}\right]}{\operatorname{Rl} \frac{\mathrm{V}_{2}-\mathrm{b}}{\mathrm{V}_{1-\mathrm{b}}}-\frac{\mathrm{a}}{\mathrm{T}_{1}^{2}}\left[\frac{1}{\mathrm{~V}_{2}}-\frac{1}{\mathrm{~V}_{1}}\right]}=1
$$

Now for Berthelot's real gas

$$
\eta_{\mathrm{Ber}}=1-\frac{\mathrm{Q}_{2}}{\mathrm{Q}_{1}}=\frac{\mathrm{RT}_{2} \ln \frac{\mathrm{V}_{4}-\mathrm{b}}{\mathrm{V}_{3}-\mathrm{b}}-\frac{\mathrm{a}}{\mathrm{T}_{2}}\left[\frac{1}{\mathrm{~V}_{4}}-\frac{1}{\mathrm{~V}_{3}}\right]}{\mathrm{RT}_{1} \ln \frac{\mathrm{V}_{2}-\mathrm{b}}{\mathrm{V}_{1-\mathrm{b}}}-\frac{\mathrm{a}}{\mathrm{T}_{1}}\left[\frac{1}{\mathrm{~V}_{2}}-\frac{1}{\mathrm{~V}_{1}}\right]}=1-\frac{\mathrm{T}_{2}}{\mathrm{~T}_{1}}
$$

\section{CLAUSIUS'S REAL GAS}

One criticism of the van der Waal equation is that no account is taken of the possibility that parameters a and $b$ can depend on temperature. Clausius [10] suggested the equation $\left(P+\frac{a}{T(V+c)^{2}}\right)(V-b)=R T$ in which intermolecular attraction is described as inversely proportional to temperature (Normal Clausius's real gas equation uses $\mathrm{c} \rightarrow 0$ ). But here first TdS relation for reversible isothermal expansion for Clausius's gas can be written as

$$
\mathrm{TdS}=\mathrm{dQ}=\mathrm{T}\left(\frac{\partial \mathrm{P}}{\partial \mathrm{T}}\right)_{\mathrm{V}} \mathrm{dV}=\mathrm{T}\left[\frac{\mathrm{R}}{\mathrm{V}-\mathrm{b}}+\frac{\mathrm{a}}{\mathrm{T}^{2}(\mathrm{~V}+\mathrm{c})^{2}}\right] \mathrm{dV}
$$


Now for adiabatic expansion and contraction of real gas $\mathrm{C}_{\mathrm{V}}$ varies with volume $\mathrm{V}$ as $\left(\frac{\partial \mathrm{C}_{\mathrm{V}}}{\partial \mathrm{V}}\right)_{T}=\mathrm{T}\left(\frac{\partial^{2} \mathrm{P}}{\partial \mathrm{T}^{2}}\right)_{V}$ and for Clausius's real gas $\left(\frac{\partial \mathrm{C}_{\mathrm{V}}}{\partial \mathrm{V}}\right)_{\mathrm{T}}=\mathrm{T}\left[\frac{\partial^{2}}{\partial \mathrm{T}^{2}}\left(\frac{\mathrm{RT}}{\mathrm{V}-\mathrm{b}}-\frac{\mathrm{a}}{\mathrm{T}\{\mathrm{V}+\mathrm{c}\}^{2}}\right)\right]_{\mathrm{V}}=-\frac{2 \mathrm{a}}{\mathrm{T}^{2}(\mathrm{~V}+\mathrm{c})^{2}}$ gives $\mathrm{C}_{\mathrm{V}}=\mathrm{f}(\mathrm{T})+\frac{2 \mathrm{a}}{\mathrm{T}^{2}(\mathrm{~V}+\mathrm{c})^{2}}$. We apply this to Carnot cycle in TS diagram of figure 1 from point A with coordinate $\left(S_{1}, T_{1}\right)$ to $B$ with coordinate $\left(S_{2}, T_{1}\right)$ to calculate the heat extracted will be

$$
\mathrm{Q}_{1}=\int_{\mathrm{A}}^{\mathrm{B}} \mathrm{TdS}=\int_{\mathrm{V}_{1}}^{\mathrm{V}_{2}} \mathrm{~T}\left(\frac{\partial \mathrm{P}}{\partial \mathrm{T}}\right)_{\mathrm{V}} \mathrm{dV}=\int_{\mathrm{V}_{1}}^{\mathrm{V}_{2}}\left[\frac{\mathrm{RT}_{1}}{\mathrm{~V}-\mathrm{b}}+\frac{\mathrm{a}}{\mathrm{T}_{1}(\mathrm{~V}+\mathrm{c})^{2}}\right] \mathrm{dV}=\mathrm{RT}_{1} \ln \frac{\mathrm{V}_{2}-\mathrm{b}}{\mathrm{V}_{1}-\mathrm{b}}-\frac{\mathrm{a}}{\mathrm{T}_{1}}\left(\frac{1}{\mathrm{~V}_{2}+\mathrm{c}}-\frac{1}{\mathrm{~V}_{1}+\mathrm{c}}\right)
$$

For the second isotherm in $T S$ diagram of figure 1 from point $\mathrm{C}$ with coordinate $\left(\mathrm{S}_{2}, \mathrm{~T}_{2}\right)$ to $\mathrm{D}$ with coordinate $\left(\mathrm{S}_{1}, \mathrm{~T}_{1}\right)$ to calculate the heat released will be

$$
\mathrm{Q}_{2}=\int_{\mathrm{C}}^{\mathrm{D}} \mathrm{TdS}=\int_{\mathrm{V}_{3}}^{\mathrm{V}_{4}} \mathrm{~T}\left(\frac{\partial \mathrm{P}}{\partial \mathrm{T}}\right)_{\mathrm{V}} \mathrm{dV}=\int_{\mathrm{V}_{3}}^{\mathrm{V}_{4}}\left[\frac{\mathrm{RT}_{2}}{\mathrm{~V}-\mathrm{b}}+\frac{\mathrm{a}}{\mathrm{T}_{2}(\mathrm{~V}+\mathrm{c})^{2}}\right] \mathrm{dV}=\mathrm{RT}_{2} \ln \frac{\mathrm{V}_{4}-\mathrm{b}}{\mathrm{V}_{3}-\mathrm{b}}-\frac{\mathrm{a}}{\mathrm{T}_{2}}\left(\frac{1}{\mathrm{~V}_{4}+\mathrm{c}}-\frac{1}{\mathrm{~V}_{3}+\mathrm{c}}\right)
$$

For the other two isentropic or adiabatic from $\mathrm{B}$ to $\mathrm{C}$ and $\mathrm{D}$ to $\mathrm{A}$ we get from first law of thermodynamics

Or,

$$
\mathrm{dQ}=0 \Rightarrow \mathrm{C}_{\mathrm{V}} \mathrm{dT}+\mathrm{T}\left(\frac{\partial \mathrm{P}}{\partial \mathrm{T}}\right)_{\mathrm{V}} \mathrm{dV}=0
$$

$$
\left[f(T)+\frac{2 a}{T^{2}(V+c)}\right] d T+T\left[\frac{R}{V-b}+\frac{a}{T^{2}(V+c)^{2}}\right] d V=0
$$

Integrating factor of this equation with $\mathrm{m}=\mathrm{f}(\mathrm{T})+\frac{2 \mathrm{a}}{\mathrm{T}^{2}(\mathrm{~V}+\mathrm{c})}$ and $\mathrm{n}=\frac{\mathrm{RT}}{\mathrm{V}-\mathrm{b}}+\frac{\mathrm{a}}{\mathrm{T}(\mathrm{V}+\mathrm{c})^{2}}$ is $\mathrm{n}^{-1}\left[\frac{\partial \mathrm{m}}{\partial \mathrm{V}}-\frac{\partial \mathrm{n}}{\partial \mathrm{T}}\right] \rightarrow-\mathrm{T}^{-1}$. We make the above equation total differential as

Or,

$$
\begin{aligned}
& -\left[\frac{\mathrm{f}(\mathrm{T})}{\mathrm{T}}+\frac{2 \mathrm{a}}{\mathrm{T}^{3}(\mathrm{~V}+\mathrm{c})}\right] \mathrm{dT}-\left[\frac{\mathrm{R}}{\mathrm{V}-\mathrm{b}}+\frac{\mathrm{a}}{\mathrm{T}^{2}(\mathrm{~V}+\mathrm{c})^{2}}\right] \mathrm{dV}=0 \\
& \mathrm{~d}\left[\mathrm{~F}(\ln \mathrm{T})+\mathrm{R} \ln (\mathrm{V}-\mathrm{b})-\frac{\mathrm{a}}{\mathrm{T}^{2}(\mathrm{~V}+\mathrm{c})}\right]=0 \\
& \mathrm{~F}(\ln \mathrm{T})+\mathrm{R} \ln (\mathrm{V}-\mathrm{b})-\frac{\mathrm{a}}{\mathrm{T}^{2}(\mathrm{~V}+\mathrm{c})}=\mathrm{constant}=\mathrm{c} \\
& \mathrm{f}(\mathrm{T})=\mathrm{c}-\mathrm{F}(\ln \mathrm{T})=\mathrm{R} \ln (\mathrm{V}-\mathrm{b})=\frac{\mathrm{a}}{\mathrm{T}^{2}(\mathrm{~V}+\mathrm{c})}
\end{aligned}
$$

Or,

Or,

Hence at $B \quad f\left(T_{1}\right)=R \ln \left(V_{2}-b\right)-\frac{a}{T_{1}^{2}\left(V_{2}+c\right)}$ and at $C f\left(T_{2}\right)=R \ln \left(V_{3}-b\right)-\frac{a}{T_{2}^{2}\left(V_{3}+c\right)}$. Thus

Similarly for D and A

$$
F\left(T_{1}\right)-f\left(T_{2}\right)=R \ln \frac{V_{2}-b}{V_{3}-b}-\frac{a}{T_{1}^{2}\left(V_{2}+c\right)}+\frac{a}{T_{2}^{2}\left(V_{3}+c\right)}
$$

Equating we get

$$
\mathrm{f}\left(\mathrm{T}_{1}\right)-\mathrm{f}\left(\mathrm{T}_{2}\right)=\mathrm{R} \ln \frac{\mathrm{V}_{1}-\mathrm{b}}{\mathrm{V}_{4}-\mathrm{b}}-\frac{\mathrm{a}}{\mathrm{T}_{1}^{2}\left(\mathrm{~V}_{1}+\mathrm{c}\right)}+\frac{\mathrm{a}}{\mathrm{T}_{2}^{2}\left(\mathrm{~V}_{4}+\mathrm{c}\right)}
$$

Or,

$$
\begin{aligned}
& \mathrm{R} \ln \frac{\mathrm{V}_{2}-\mathrm{b}}{\mathrm{V}_{3}-\mathrm{b}}-\frac{\mathrm{a}}{\mathrm{T}_{1}^{2}\left(\mathrm{~V}_{2}+\mathrm{c}\right)}+\frac{\mathrm{a}}{\mathrm{T}_{2}^{2}\left(\mathrm{~V}_{3}+\mathrm{c}\right)}=\mathrm{R} \ln \frac{\mathrm{V}_{1}-\mathrm{b}}{\mathrm{V}_{4}-\mathrm{b}}-\frac{\mathrm{a}}{\mathrm{T}_{1}^{2}\left(\mathrm{~V}_{1}+\mathrm{c}\right)}+\frac{\mathrm{a}}{\mathrm{T}_{2}^{2}\left(\mathrm{~V}_{3}+\mathrm{c}\right)} \\
& \mathrm{R} \ln \frac{\mathrm{V}_{4}-\mathrm{b}}{\mathrm{V}_{3}-\mathrm{b}}-\frac{\mathrm{a}}{\mathrm{T}_{2}^{2}}\left[\frac{1}{\mathrm{~V}_{4}+\mathrm{c}}-\frac{1}{\mathrm{~V}_{3}+\mathrm{c}}\right]=\mathrm{R} \ln \frac{\mathrm{V}_{1}-\mathrm{b}}{\mathrm{V}_{2}-\mathrm{b}}-\frac{\mathrm{a}}{\mathrm{T}_{1}^{2}}\left[\frac{1}{\mathrm{~V}_{1}+\mathrm{c}}-\frac{1}{\mathrm{~V}_{2}+\mathrm{c}}\right]
\end{aligned}
$$

$$
\frac{\operatorname{Rln} \frac{\mathrm{V}_{4}-\mathrm{b}}{\mathrm{V}_{3}-\mathrm{b}}-\frac{\mathrm{a}}{\mathrm{T}_{2}^{2}}\left[\frac{1}{\mathrm{~V}_{4}+\mathrm{c}}-\frac{1}{\mathrm{~V}_{3}+\mathrm{c}}\right]}{\operatorname{Rln} \frac{\mathrm{V}_{2}-\mathrm{b}}{\mathrm{V}_{1-b}}-\frac{\mathrm{a}}{\mathrm{T}_{1}^{2}}\left[\frac{1}{\mathrm{~V}_{2}+\mathrm{c}}-\frac{1}{\mathrm{~V}_{1}+\mathrm{c}}\right]}=1
$$

Considering absolute value we get for Clausius's real gas equation

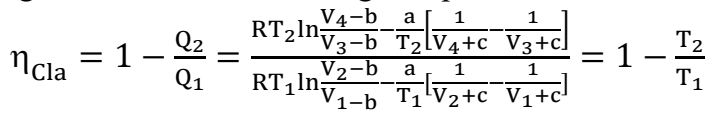

\section{DISCUSSIONS AND REMARKS}

(i) If $T_{1} \rightarrow T_{2}$ we have $\eta \rightarrow 0$. So no machine can work if the source and sink are at the same temperature. It proves that perpetual motion of second kind is impossible.

(ii) If $T_{1} \gg T_{2}$, i.e. if $T_{2} \rightarrow 0$ then $\eta \leq 1$. So efficiency of a Carnot engine is always less than unity and its maximum ideal value is unity.

(iii) If $T_{1}=T$ and $T_{2}=T-d T$, then $\eta=\frac{d W}{d Q}=\frac{d T}{T}$.

(iv) $\mathrm{Q}_{1}=\mathrm{RT}_{1} \ln \frac{\mathrm{V}_{2}}{\mathrm{~V}_{1}}$ and $\mathrm{Q}_{2}=\mathrm{RT}_{2} \ln \frac{\mathrm{V}_{3}}{\mathrm{~V}_{4}}=\mathrm{RT}_{2} \ln \frac{\mathrm{V}_{2}}{\mathrm{~V}_{1}}$ gives the definition of entropy as $\frac{\mathrm{Q}_{1}}{\mathrm{~T}_{1}}=\frac{\mathrm{Q}_{2}}{\mathrm{~T}_{2}}=\mathrm{R} \ln \frac{\mathrm{V}_{2}}{\mathrm{~V}_{1}}$.

(v) Efficiency of Carnot engine depends only on the temperatures of source and sink. So this engine is independent of the nature of the working substance.

\section{CONCLUSION}

Three simple and old real gas equations are tested here to show the independence of working substance as any real gas. From one real gas to other variation of specific heat at constant volume $\mathrm{C}_{\mathrm{V}}$ show different forms. This makes great difficulties to show independence of working substance. For the reason we use Maxwell's first TdS relation. The method used here is a good pedagogic problem for different real gas equations. It is a good 
undergraduate problem for students and more such may be visualized. People will generally encourage the young scientific brains to cop up with new and novel pedagogic works based on their skill to nurture undergraduate physics.

\section{ACKNOWLEDGEMENT}

The first author did a small part of this work in the year 2017-18 under the DBT Star College scheme from Maulana Azad College, Kolkata-13 and completed this whole work as online project fellow under supervision of Dr. A. Ghorai at School of Science, Block 1/3G, 66/63 Jangalpur Road, Kolkata-81. Authors gratefully acknowledge this.

\section{REFERENCES}

[1] David Halliday, Robart Resnick and Jearl Walker, Fundamentals of Physics, John Willy \& sons, 674-679, 1960.

[2] M. N. Saha and B. N. Srivastave, A Tretise on Heat, The Indiasn Press Pvt. Ltd. 230-243, 1958.

[3] M. W Zemansky and Richard Dittman, Heat and Thermodynamics, McGraw Hill, 1981.

[4] Enrico Fermi, Thermodynamics, Dover Pub, 1956.

[5] F. Rief, Fundaentals of Statistical and Thermal Physics, McGraw Hill, 1965.

[6] D. C. Agrawal and V. J. menon, "The Carnot Cycle with the Van der Waals Equation of State”, Eur. J. Phys. Vol.11, pp.88-90,1990.

[7] Paulus C. Tjiang and Sylvia H. Sutanto, "Efficiency of Carnot Cycle with Arbitrary Gas Equation of State", arXive/0601173v4.

[8] A. A. Sobko, "Generalised Van der Waals-Berthelot Equation of state", Doklady Physics, Vol.53, Issue.5, pp.416419, 2008.

[9] A. A. Sobko, "Description of Evaporation Curve by the Generalised Van der Waal-Berthelot Equation. Part I", Journal of Physical Science and application, Vol.4, Issue.8, pp.524-530, 2014.doi:10.17265/2159-5348/2014.08

[10] Jaime Wisniak, "Daniel Berthelot. Part I. Contribution to thermodynamics", para quitarle el polvo Educ. Quim. Vol.21, Issue.2, pp.155-162, 2010. 